\title{
PARADIGMAS POSITIVISTAS NAS REFORMAS EDUCACIONAIS DO (DES)GOVERNO TEMER: DO ESCOLA SEM PARTIDO AO NOVO ENSINO MÉDIO
}

\author{
LOS PARADIGMAS POSITIVISTAS EN LAS REFORMAS EDUCATIVAS DEL GOBIERNO \\ TEMER: DE LA ESCUELA SIN PARTIDO A LA NUEVA ENSEÑANZA MEDIA
}

\author{
POSITIVIST PARADIGMS IN THE EDUCATIONAL REFORMS OF THE (DES) \\ GOVERNMENT TEMER: FROM SCHOOL WITHOUT PARTY TO NEW MIDDLE \\ SCHOOL
}

Renan dos Santos Sperandio

Ana Carolina Henriques do Nascimento Muniz

\begin{abstract}
Resumo: O presente artigo pretende contextualizar a crise política atual no Brasil e realizar apontamentos sobre o movimento Escola Sem Partido e a Reforma do Ensino Médio do governo Temer. Nossa escolha justifica-se, por tais projetos expressarem uma "nova" forma de pensar o Estado, a escola e os movimentos civis sob uma lógica cada vez mais regulada, e sob uma concepção de controle dos currículos e propostas pedagógicas que destoam de todas as elaborações já produzidas em outros países que tendem a caminhar para uma perspectiva da gestão democrática, e que em nada tem a ver com tais propostas. Contextualizado a política em crise no Brasil, apresentadas as propostas de ambos os projetos, e explicitado o motivo da junção das proposições legislativas em análises, partimos para a averiguação da veracidade de seus argumentos e dos possíveis caminhos que modernizariam a educação e resolveriam o problema de déficit de aprendizagem que temos. Ao analisarmos os critérios para a aplicação de tais medidas, compreendemos que tanto o projeto de reforma do Ensino Médio, quando o programa "Escola sem Partido" partem de análises rasas da realidade. As mudanças propostas pela Lei 13. 415/2017 e o PL 867/2015, escamoteiam a verdade, confundem a comunidade escolar, desfocam o real problema da educação básica, principalmente do Ensino Médio.
\end{abstract}

Palavras-Chaves: Positivismo; Reforma Educacional; Escola Sem Partido; Ensino Médio

Resumen: El presente artículo pretende contextualizar la crisis política actual en Brasil y realizar apuntes sobre el movimiento Escuela Sin Partido y la Reforma de la Enseñanza Media del Gobierno Temer. Nuestra elección se justifica, por tales proyectos expresar una "nueva" forma de pensar el Estado, la escuela y los movimientos civiles bajo una lógica cada vez más regulada, y bajo una concepción de control de los currículos y propuestas pedagógicas que desatan de todas las Elaboraciones ya producidas en otros países que tienden a caminar hacia una perspectiva de la gestión democrática, y que no tiene nada que ver con tales propuestas. En el contexto de la política en crisis en Brasil, presentadas las propuestas de ambos proyectos, y explicitado el motivo de la unión de las proposiciones legislativas en análisis, partimos para la averiguación de la veracidad de sus argumentos y de los posibles caminos que modernizarían la educación y resolverían el problema de El déficit de aprendizaje que tenemos. Al analizar los criterios para la aplicación de tales medidas, comprendemos que tanto el proyecto de reforma de la Enseñanza Media, cuando el programa "Escuela sin Partido" parten de análisis escasos de la realidad. Los cambios propuestos por la Ley 13. 415/2017 y el PL 867/2015, escamotean la verdad, confunden a la comunidad escolar, desenfocan el real problema de la educación básica, principalmente de la Enseñanza Media.

Palavras-Chaves: Positivismo; Reforma Educacional; Escola Sem Partido; Ensino Médio

Abstract : This article presents contextualize the current political crisis in Brazil and make notes on the movement No School Party and the Reformation of the Secondary Education of the Temer government. Our choice is justified, because such projects express a "new" way of thinking about the State, the school and civil movements under an increasingly regulated logic, and under a conception of control of the curricula and pedagogical proposals that 
disprove of all the Elaborations already produced in other countries that tend to move towards a democratic management perspective, and that has nothing to do with such proposals. In the context of the crisis policy in Brazil, presented the proposals of both projects, and explained the reason for joining the legislative proposals in analysis, we set out to investigate the veracity of their arguments and possible ways that would modernize education and solve the problem of Learning deficit we have. When analyzing the criteria for the application of such measures, we understand that both the project of reform of High School, and the program "School without Party" start from shallow analyzes of reality. The changes proposed 13, 415/2017 and PL 867/2015, conceal the truth, confuse the school community, blur the real problem of basic education, especially in High School

Keywords: Positivism; Educational Reform; School Without Party; High school

\section{Introdução}

A educação sempre está presente nas propostas de qualquer governante que queira pleitear algum cargo na esfera executiva. O discurso é quase unívoco e as intenções são sempre as melhores. Da "Pátria Educadora" ao "Ordem e Progresso" as promessas proferidas são as de que os professores, pais e alunos podem ficar tranquilos, pois a mão do Estado cuidará do futuro de nossas crianças e jovens. Mas passado o calor dos debates e percebida as ilusões das promessas, o discurso ornamentado toma forma de um projeto educacional que é estruturado a partir de medidas provisórias, projetos de leis, portarias, que tornam real o projeto ideal de uma educação "para todos". Como um maestro na orquestra, tais projetos e medidas regem como a banda da política educacional tocará. E neste espetáculo, quem paga o "show" tem escolhido a música. Ou seja, na sinfonia da política educacional, institutos e entidades internacionais, vêm ao longo dos anos dando as notas que devem gerenciar a educação brasileira e mundial.

Não se trata de um erro afirmar que o sistema educacional brasileiro precisa de reformas, inclusive reformas estruturais e profundas, capazes de possibilitar um salto qualitativo nos índices educacionais do nosso pais. De acordo com os dados do "Qedu", o índice de reprovações no Ensino Médio em 2016 esteve em torno de 11,6\%, equivalendo a 922.910 alunos reprovados. Além destes, 6,8\%; ou seja, 545. 949 abandonaram a escola.

Além disto, aproximadamente 1,5 milhão são jovens de 15 a 17 anos que deveriam estar cursando o Ensino Médio. Diante deste cenário de evasão e reprovação, vale ressaltar o desafio da universalização do ensino que estava posto para ser alcançado até 2016, conforme Emenda Constitucional $n^{\circ} 59$.

Os defensores da Reforma do Ensino Médio, expresso na Lei 13. 415 de 16 de Fevereiro de 2017, argumentam que para resolver os maus índices da última etapa da Educação Básica é necessário mudanças na composição curricular para que os problemas possam começar a ser sanados. Os defensores do projeto "Escola sem Partido", acreditam que o problema é que os professores não estão fazendo suas funções como deveriam, utilizando o espaço de sala de aula para, segundo eles, doutrinarem seus alunos com ideias político-partidárias. Para os integrantes desse "movimento" é preciso que a escola assuma um papel de neutralidade diante de questões políticas morais e religiosas, e que, só assim será possível garantir acesso a um saber realmente útil para os alunos.

Todavia, existe uma gama de pensadores e intelectuais da área da educação que entendem que tais proposições, apesar da aparente boa intenção, está essencialmente carregada de incompreensões do 
tema, desviando o real problema da educação. Diante desse cenário conflituoso, típico da conjuntura de acirramento entre interesses antagônicos para a sociedade, precisamos pôr em prova tais proposições que dizem resolver o problema da educação.

Assim sendo, num primeiro momento, realizamos um balanço crítico da conjuntura política do Brasil, identificando os motivos que envolvem o impeachment da presidente Dilma Roussef - PT e a posse de seu vice, Michel Temer - PMDB, procurando compreender as reformas educacionais aqui estudadas (Reforma do Ensino Médio e o Projeto Escola sem Partido) como resultado de uma crise política que se estende desde o início do segundo mandatado da então presidenta petista.

Em seguida usaremos a combinação de dados que partem de duas fontes: A Fonte $\mathbf{0 1}$ se refere ao PL 13. 415/2017 e uma breve análise de dispositivos legais anteriores que o compuseram, bem como os argumentos usados para defender a necessidade da reforma do Ensino Médio, nos marcos regulamentados pela referida lei. A Fonte 02 que é composta pelo Projeto de Lei 193/2016 do Senado Federal, que é uma expressão legal do que o movimento "Escola Sem Partido" reivindica como critério para se ter uma escola sem influência partidária e os argumentos usados para defender a necessidade de uma escola nos marcos do que o projeto de lei vem apresentando. Feito isso, em um momento posterior faremos uma contraposição aos argumentos apresentados, procurando identificar alguns elementos capazes de atestar sua verdade.

\section{O Governo Temer: Um governo de continuidade ao projeto Neoliberal}

O ano de 2016 foi um marco para a história política do Brasil. O impeachment da presidenta Dilma Roussef, acusada de cometer crime de responsabilidade fiscal, consumado no dia 31 de Agosto, faz com que os rumos do país passassem a ser definidos pelo vice de chapa, Michel Temer. Este possui um currículo com denúncias graves de corrupção e mesmo com tantos indícios de desonestidade ocupa o maior cargo do executivo nacional.

Não bastasse tais denúncias, o presidente Temer é também indiciado pela Procuradoria Geral da República por obstrução da Justiça e por organização criminosa. No entanto, segundo o próprio presidente, tais denúncias são irrelevantes, pois o que é urgente não é se defender de tais acusações, mas, cumprir o papel que lhe é devido: Garantir os ajustes necessários para fazer, segundo ele, o país voltar a crescer.

A fórmula quase mágica deste crescimento não está na taxação das grandes fortunas dos $1 \%$ dos brasileiros mais ricos; ou seja, os que possuem uma fortuna acima dos 4 bilhões de reais, o que geraria uma receita de cerca de 10 bilhões anuais, tampouco na auditoria da dívida pública - e não estamos falando de calote, mas de um direito que é o de revisar as contas e negociar os juros sobre juros - que também renderiam mais 962 bilhões de Reais. Tais medidas "salvadoras", não estão nos marcos de cobrar débitos de impostos das empresas ao governo que já ultrapassa a casa dos $\mathrm{R} \$ 545$ bilhões, nem reduzir o orçamento que é destinado ao Congresso Nacional, que custa anualmente mais de $\mathrm{R} \$ 28,8$ bilhões dos cofres públicos. Nenhuma dessas possibilidades é apresentada pelo presidente. 
Diante de tal cenário calamitoso, muitos intelectuais, do chamado campo progressista, concluem que tal conjuntura desfavorável é resultado de um golpe de Estado que se deu sob um novo formato, para a aplicação de uma agenda neoliberal agressiva que só poderia ter êxito com a saída da presidente Dilma Roussef.

Jinkings (2016) afirma as chamadas pedaladas fiscais, que foram interpretadas como crime de responsabilidade fiscal, eram práticas que aconteciam em vários governos e nunca haviam sido motivo de impedimento do representante do executivo. E que o processo de impeachment teria o objetivo de “concretizar um processo de concentração de renda e retirada de direitos duramente conquistados pelas camadas mais pobres do país ao longo de anos de luta." (JINKINGS, 2016, p. 13)”.

Porém, para Godeiro (2014),

Não houve nenhuma mudança estrutural nas causas das desigualdades sociais no país. Produzimos muitas riquezas; apenas os trabalhadores de seis países produziram mais riquezas que os trabalhadores brasileiros, porém, na distribuição desta riqueza estamos na rabeira: 84 países estão na frente do Brasil (GODEIRO, 2014, p. 07).

Segundo informações do Anuário Estatístico de 2012 do Ministério de Minas e Energia baseado em dados do IBGE, Banco Mundial e ONU, os trabalhadores brasileiros produziram 12,7 mil dólares em 2011, e neste mesmo ano o Brasil estava entre os países mais desiguais do mundo.

Biondi (2017), cita Pachukanis para apontar que o Estado, como organização classista de dominação e como organização para a condução de guerras externas, não exige uma interpretação jurídica e, por essência, não a admite. Essa é uma área em que reina a assim chamada raison d'état, ou seja, o princípio de estrita conveniência. Para Biondi (idem), um golpe seria uma quebra no padrão de funcionamento do regime, o que no caso do impedimento da presidente Dilma, não aconteceu.

Pouco importa, sob o ponto de vista da luta real entre os antagonistas no sistema político, se houve cometimento de crime ou não. Um governo que cai é um governo que não se sustenta, que carece de aliados em número suficiente para mantê-lo no jogo. A escolha dos motivos "oficiais" do impedimento é secundária. O que importa, na realidade, é a disputa encarniçada pelo poder. [...]E o que conta, na vida real, é esse elemento político material (o modo como os órgãos de poder se relacionam entre si), e não os pareceres dos juristas sobre a legalidade ou ilegalidade de determinados atos e procedimentos.

Inclusive, o projeto de Reforma de Ensino Médio tem sua primeira expressão a partir do PL 6.840 do Deputado Reginaldo Lopes do PT-MG. Na campanha presidencial para o pleito de 2014, a própria presidente afirmou ser favorável a uma reforma do Ensino Médio que o tornasse mais interessante. A crise burguesa diante do acirramento da luta de classes tem se mostrado tão grande, que o próprio ministro de Temer, Mendonça Filho (DEM-PE), se pronunciou contrário ao projeto "Escola Sem Partido".

No entanto, tanto um quanto outro, promovem de formas diferenciadas, um desmonte da educação pública e um cerceamento do professor. Ambos escamoteiam o verdadeiro problema. A Lei 13. 415/17 diz que o problema do EM é o currículo enrijecido e propõe uma maior flexibilização deste, já o PL867/2015 identifica o problema da educação como sendo um desvio da função do professor que em vez de ensinar "doutrina" seus alunos. O que nem um nem outro falam é sobre o financiamento 
educacional, sobre as teorias pedagógicas que há anos negam um saber sistematizado e socialmente referenciado aos seus alunos e formam um conluio para com o discurso de novidade desestruturar todo um sistema educacional.

\section{As justificativas da reforma: Modernizar o velho para matar o novo.}

Os defensores da Reforma do Ensino Médio, expresso na Lei 13. 415 de 16 de Fevereiro de 2017, argumentam que para resolver os maus índices da última etapa da Educação Básica é necessário mudanças na composição curricular para que os problemas possam começar a ser sanados. Os defensores do projeto "Escola sem Partido", acreditam que o problema é que os professores não estão fazendo suas funções como deveriam, utilizando o espaço de sala de aula para, segundo eles, doutrinarem seus alunos com ideias político-partidárias. Para os integrantes desse "movimento" é preciso que a escola assuma um papel de neutralidade diante de questões políticas morais e religiosas, e que, só assim será possível garantir acesso a um saber realmente útil para os alunos.

Tentando averiguar tais assertivas, analisamos a Fonte 01, e destacamos alguns artigos da legislação que elucidam as mudanças propostas, bem como as justificativas de quem defende que tais mudanças ocorram.

A primeira mudança proposta pela Lei 13. 415/2017 diz respeito a carga horária que passa de $800 \mathrm{~h}$ ano para $1.400 \mathrm{~h}$. A justificativa apresentada pela Secretária Executiva do MEC, Maria Helena Guimarães de Castro é de que tal medida cria uma jornada integral, com no mínimo sete horas diárias e integra a educação profissional ao currículo regular. Também segundo o Ministro da Educação, Mendonça Filho, este aumento de carga horária, nos marcos da Reforma se justifica para diminuir as desigualdades e combater o desinteresse dos jovens.

Também de acordo com a Reforma, o Ensino Médio passa a ser organizado por módulos. Vale ressaltar que antes o Ensino Médio era organizado em séries anuais, períodos semestrais, ciclos, alternância regular de períodos de estudos, grupos não-seriados, com base na idade, na competência e em outros critérios, ou por forma diversa de organização, sempre que o interesse do processo de aprendizagem assim recomendava. Esta mudança foi aplaudida por Rafael Lucchesi, da CNI, que defende uma organização do Ensino Médio mais flexível. Utilizando o exemplo da Alemanha que, segundo ele, organiza sua educação de modo que os alunos que cursem determinadas disciplinas no curso técnico, por exemplo, conseguem eliminar disciplinas que já cursaram no nível médio. Para Lucchesi, em audiência pública realizada no dia 04 de Junho de 2016 na Câmara dos Deputados, os alunos que estão nos cursos superiores na Alemanha quando deixam os cursos, aproveitam as disciplinas cursadas, certificando-se como um técnico ou tecnólogo.

Há também na reforma do Ensino Médio o reconhecimento do profissional da educação que possua notório saber. Maria Helena Guimarães de Castro afirmou que a formação inicial dos professores não é boa e, portanto, não prepara o professor para o mundo real, tampouco para a prática didática. Desta 
forma a qualidade das aulas e o conhecimento dos alunos, segundo ela, não serão afetados pelo notório saber.

Os itinerários formativos, a serem ofertado por diversos arranjos curriculares e conforme relevância e possibilidade dos sistemas de ensino, poderão ser realizados com parceiras e convênios com instituições de educação, inclusive as que atuam com educação à distância. Essa parceria permite que se uma determinada escola não disponibilizar todos os itinerários formativos - acreditamos que é muito provável que isso ocorra - o aluno possa cursá-lo em outra instituição e isso ser validado sem nenhum prejuízo. Ou, ainda, que a própria secretaria de educação do Estado, firme convênios com empresas como SESI, SENAI, SENAC e outras instituições do ramo, para que os alunos da rede cursem os itinerários formativos nestes espaços, de modo que isso seja aproveitado para o currículo do aluno.

Apresentada a Fonte 01, passaremos para a exposição da Fonte 02, que é compreendida pelo PL 867/2015, que inclui entre as diretrizes e bases da educação nacional, o "Programa Escola Sem Partido". O "Programa Escola Sem Partido" parte de do pressuposto que o professor tem seis deveres; sendo eles: 1) O Professor não se aproveitará da audiência cativa dos alunos, com o objetivo de cooptá-los para esta ou aquela corrente política, ideológica ou partidária. 2) O Professor não favorecerá nem prejudicará os alunos em razão de suas convicções políticas, ideológicas, morais ou religiosas, ou da falta delas. 3) O Professor não fará propaganda político-partidária em sala de aula nem incitará seus alunos a participar de manifestações, atos públicos e passeatas. 4) Ao tratar de questões políticas, socioculturais e econômicas, o professor apresentará aos alunos, de forma justa - isto é, com a mesma profundidade e seriedade -, as principais versões, teorias, opiniões e perspectivas concorrentes a respeito. 5) O Professor respeitará o direito dos pais a que seus filhos recebam a educação moral que esteja de acordo com suas próprias convicções. 6) O Professor não permitirá que os direitos assegurados nos itens anteriores sejam violados pela ação de terceiros, dentro da sala de aula.

Apresentada as fontes e explicitado o motivo da junção das proposições legislativas em análises, partimos para a averiguação da veracidade de seus argumentos e dos possíveis caminhos que propõem modernizar a educação e resolver o problema de déficit de aprendizagem que temos.

Ao analisarmos os critérios para a aplicação dos projetos, podemos afirmar que ambos partem de análises rasas da realidade. A justificativa que se dá para a repentina mudança do Ensino Médio, é a urgência da matéria e a necessidade de garantir uma educação melhor para o jovem que tem pressa. Aqui lembramos de um famoso ditado popular, "a pressa é inimiga da perfeição".

A Secretária Executiva do MEC afirma que a reforma do Ensino Médio já vinha sendo discutida há anos no congresso e que uma proposta de lei já havia sido elaborada no ano de 2013, o PL 6.80/13 do deputado Reginaldo Lopes (PT-MG), mas permanecia estagnada. Para agilizar o processo e resolver o problema, o ministro do governo Temer, que deseja ser conhecido como o presidente das grandes reformas, mostra a que veio e com uma "canetada", "soluciona" o problema da educação.

Que bom seria se esta vontade de fazer do país uma pátria educadora na base dos decretos e medidas provisórias, desse conta dos problemas das 13 mil escolas sem energia elétrica que o Brasil possui. Apenas $0,6 \%$ das escolas brasileiras têm infraestrutura próxima da ideal para o ensino,e $44 \%$ de 
escolas que contam apenas com água encanada, sanitário, energia elétrica, esgoto e cozinha em sua infraestrutura.

Insistimos, se menos de $1 \%$ das escolas possuem estrutura adequada para o ensino, como será possível garantir flexibilização curricular, escolha de itinerários formativos, se temos escolas nas quais quando não falta professor, falta material, quando há material, falta mobiliário, e quando aparenta ter tudo, há ausência de uma estrutura adequada nos prédios escolares? Como garantir a integração nestas escolas? Tais políticas deveriam vim articuladas de grandes investimentos, como afirma a própria secretária executiva do MEC Helena Guimarães de Castro. Porém o que recebemos como garantia de que o projeto de reforma do Ensino Médio já nasce morto, é a PEC 241 que limita os gastos públicos para garantir um superávit que pague a fraudulenta dívida pública, que não passa de juros sobre juros e valores que ultrapassam o real débito da nação.

Se a Reforma do EM, na atual conjuntura é inviável, o projeto "Escola sem Partido" é uma piada de mau gosto. A ideia de neutralidade que ele vem trazendo é um conceito inteiramente questionável, principalmente quando se trata de relações humanas, trocas de experiências e diálogo. Não estamos tratando de uma experiência com ratos em que se pode anotar as reações e os comportamentos e observar sem interferir. O processo de ensino-aprendizagem pressupõe a troca, o diálogo, a relação professor-aluno e essa relação em si é política.

O significado da palavra política, a partir da definição do dicionário Aurélio, é a habilidade no trato das relações humanas e é também a arte de governar os negócios públicos ou debater sobre estes negócios. E esta relação de diálogo e debate em nossa concepção, não há como não ser partidária! Talvez não seja partidária no sentido da sigla, mas o termo partidário diz respeito a tomar partido, que nada mais é que uma associação de pessoas unidas pelos mesmos interesses e ideias. Ou seja, a própria proposição de uma escola "sem partido" é um posicionamento político, um posicionamento que tem apoio de uma associação de pessoas com o interesse de se ter uma escola "sem doutrinação". Porém, se tais proposições não são políticas e de cunho partidário, questionamos, são o quê?

A ideia de neutralidade nos remete a ideais positivistas. Segundo Costa (2012), o movimento positivista acreditava num ideal de neutralidade; ou seja, na separação entre o pesquisador/autor e sua obra. Para os positivistas o conhecimento se explica por si mesmo, necessitando apenas que o seu estudioso o recupere e o coloque à mostra com o auxílio do empírico.

A partir do exposto, podemos afirmar que uma ideia do século XIX, cabe perfeitamente na proposta do "Escola sem Partido", em pleno século XXI. O discurso que nos apresentam é que tais medidas visam modernizar a educação e deixar a escola mais eficiente, menos ideológica, longe de qualquer envolvimento, buscando um conhecimento objetivo, que também é neutro; ou seja, sem qualquer influência partidária. Os ideólogos do projeto sem partido, pensam em um tipo de aluno e de escola que não existe na realidade.

O projeto "Escola sem Partido" cria uma proposta pedagógica que é inviável de acontecer. Inviável, principalmente pelo ponto de vista estrutural. O respeito as individualidades de crença e moral de cada aluno, pode levar a um entendimento que o aluno não poderá ter contato com outras expressões 
religiosas e morais que não as "escolhidas" pelo pai. Um pai cristão, por exemplo, pode chegar a uma conclusão que o debate sobre as religiões de matrizes africanas seja uma afronta para sua liberdade de religião, e uma sala em que existam alunos cristãos, ateus, umbandistas, budistas e agnósticos, o professor estaria numa situação delicada. Afinal, como ele sozinho conseguiria garantir a liberdade de crença de todos os seus alunos, sem que pareça um desrespeito a liberdade de religião do outro?

Por esta razão, a neutralidade passa a ser questionada. Por isso que Paulo Freire (1996, p. 41) afirma que "o espaço pedagógico, neutro por excelência, é aquele em que se treinam os alunos para práticas apolíticas, como se a maneira humana de estar no mundo fosse ou pudesse ser uma maneira neutra". O Ensino é uma transmissão intencional dos saberes produzidos historicamente pelo conjunto dos homens, como nos aponta Saviani (2011), e essa intencionalidade constitui uma ação política.

\section{Conclusão}

As mudanças propostas pela Lei 13. 415/2017 e o PL 867/2015, escamoteiam a verdade, confundem a comunidade escolar, desfocam o real problema da educação básica, principalmente do Ensino Médio. É como uma casa antiga que recebe um novo acabamento, mas não são modificadas as estruturas; ou seja, com o tempo apresenta novos problemas ocasionados pelas estruturas velhas. A pintura feita nas paredes das falhas, não deu conta de resolver os problemas estruturais da educação porque as carências escolares e educacionais de nossos jovens, em nossa maneira de compreender, não se resolvem por meio de leis e medidas provisórias.

A juventude deve, portanto, criar uma alternativa independente, a partir da luta organizada junto aos trabalhadores da educação e aos pais comprometidos com uma escola de qualidade, contra o desmonte da escola pública. Devem se organizar para a construção de uma escola laica, de qualidade, universal, com uma educação socialmente referenciada, sem qualquer expressão de racismo, fascismo, machismo e homofobia. Por uma educação integral nos marcos da escola unitária, que seja politizada, e que o único partido que não possa ter nela, seja o partido da hipocrisia, do falso moralismo e do falso apartidarismo.

Por fim, quanto mais cerceados formos, quanto mais intolerantes se mostrarem nossos alunos, mais debate político deverá ser feito. Pois como diz Freire (1996, p. 41) a presença do professor não pode passar despercebida dos alunos, pois é em si, uma presença política. E enquanto presença política não pode, e nem vai se omitir, mas, vai revelar aos alunos a sua capacidade de analisar, de comparar, de avaliar, de decidir, de optar e de romper. Romper principalmente com os grilhões da ignorância que insistem em ressurgir das trevas, querendo renovar velhas e falidas práticas, para impedir que um novo movimento tome forças e revolucione de uma vez por todas as calamidades, não só da educação, mas de toda uma nação!

\section{Referências Bibliográficas}


ANDIFES. Secretária do MEC critica formação inicial de professores e defende notório saber.

Disponível em: < http://www.andifes.org.br/secretaria-do-mec-critica-formacao-inicial-de-professores-edefende-notorio-saber/> Acesso em 17/08/2017

BIONDI, Pablo. O impeachment e a farsa do golpe: Em defesa de uma interpretação marxista da democracia liberal. 2017. Disponível em: <https://goo.gl/riRfLk> Acesso em 15/08/2017

BRASIL. Lei 9.394 de 20 de Dezembro de 1996. Estabelece as diretrizes e bases da educação nacional. Publicado no DOU de 23/12/1996. Disponível em: < https://goo.gl/p6DLpL > Acesso em 16 de Agosto de 2016

BRASIL. PL 867/2015. Institui o Programa "Escola sem Partido". Disponível em: <http://www.camara.gov.br/sileg/integras/1317168.pdf> Acesso em 17/08/2017

CAMARA DOS DEPUTAdos. Audiência Pública sobre a reforma do Ensino Médio. Disponível em: < https://goo.gl/ETFuo4> Acesso em 17/08/2017

CAMARA DOS DEPUTADOS. Você já ouviu falar na "Escola sem Partido"?. Disponível em: <https://goo.gl/y9a6qY> Acesso em 17/08/2017

COSTA. Antônio José Silva. Influência do positivismo no processo educacional. 2012. Disponível em: < https://goo.gl/XoATjV> Acesso em 17/08/2017

ÉPOCA. Entrevista com Maria Helena Guimarães sobre a Reforma do Ensino Médio. Disponível em: <https://goo.gl/jRzEtu> Acesso em 17/08/2017

ÉPOCA. Escola de tempo integral para diminuir desigualdades. Disponível em: <https://goo.gl/AFi8Qi> Acesso em 17/08/2017

ESTADÃO. Quero ser conhecido como o presidente das grandes reformas. Disponível em: $<$ http://economia.estadao.com.br/noticias/geral,quero-ser-conhecido-como-o-presidente-que-fez-asreformas-diz-temer,70001757151> Acesso em 17/08/2017

FREIRE. Paulo. Pedagogia da Autonomia: Saberes Necessários à Prática Educativa. 36. ed. São Paulo: Paz e Terra, 2007.

FRIGOTTO, Gaudêncio. Escola "sem" partido: Esfinge que ameaça a educação e a sociedade brasileira. Rio de Janeiro: UERJ, LPP, 2017. 144p. ISBN 978-85-92826-07-9. E-ISBN: 978-85-92826-062

GODEIRO, Nazareno, org. Os motivos da revolta popular: Um balanço crítico do governo do PT. São Paulo: ILAESE, 2014. ISBN: 978-8566055-00-2

JINKINGS, Ivana. O Golpe que tem vergonha de ser chamado de golpe in JINKINGS, Ivana; DORIA, Kim; CLETO, Murilo.Org. Por que gritamos golpe? Para entender o impeachment e a crise política no Brasil. $1^{a}$ ed. São Paulo: Boi tempo, 2016. ISBN: 978-85-7559-501-5

NBR. Mendonça Filho e o Novo Ensino Médio. Disponível em: <https://goo.gl/xNKGkU> Acesso em $17 / 08 / 2017$

SAVIANI. Dermeval. Pedagogia Histórico-Crítica: Primeiras aproximações. 11. ed.rev. Campinas, São Paulo: Autores Associados, 2011 (Coleção educação contemporânea)

UOL. Menos de 1\% das escolas brasileiras tem infraestrutura ideal; 2013. Disponível em: < https://goo.gl/mRX6WR> Acesso em 17/08/2017

Recebido em: 18/08/2017

Aceito em: 06/11/2017 